\title{
VIABILIDADE ECONÔMICA DE PRODUÇÃO DE LENHA DE EUCALIPTO PARA SECAGEM DE PRODUTOS AGRÍCOLAS
}

\section{PAULO C. AFONSO JÚNIOR ${ }^{1}$, DELLY OLIVEIRA FILHO ${ }^{2}$, DOUGLAS R. COSTA ${ }^{3}$}

RESUMO: Este trabalho teve como principal objetivo determinar o custo e a viabilidade de produção de lenha de eucalipto necessária para secagem de produtos agrícolas. As principais considerações técnicas e econômicas foram: a) uso de lenha de eucalipto seca em fornalha de fogo indireto; b) custos referentes à mão-de-obra, materiais, insumos e equipamentos; c) custo de oportunidade e/ou taxa de juros de $10 \%$ ao ano; d) preço médio da terra variando de 500,00 a 2.000,00 US\$ por ha; e) custo administrativo do reflorestamento de $10 \%$ sobre o custo do investimento, e f) período de investimento igual ao ciclo da produção de eucalipto, isto é, 21 anos. Concluiu-se que o investimento no reflorestamento com eucalipto é viável economicamente em terras próprias para lavoura, e, ainda, que a área utilizada para a produção de lenha é relativamente pequena, ou seja, de 0,50 a 4,23\% da área de lavoura para as culturas consideradas neste estudo: café (em coco), milho, arroz, feijão e soja.

PALAVRAS-CHAVE: energia, reflorestamento, secagem.

\section{ECONOMICAL FEASIBILITY FOR EUCALYPTUS' FIREWOOD PRODUCTION FOR DRYING OF AGRICULTURAL PRODUCTS}

\begin{abstract}
The main objective of this work was to determine the costs and economical feasibility of eucalyptus firewood production for drying of agricultural products. The main technical and economic considerations were: a) use of dried eucalyptus firewood in indirect furnaces; b) costs of manual work, materials, equipments and other inputs; c) interest or opportunity costs $10 \%$ per year; d) average land price varying from 500.00 until 2,000.00 US\$/hectare; e) forestry management costs $10 \%$ per year; f) investment period equal to the eucalyptus production cycle, that is 21 years. It was concluded that the reforestation is feasible economically, when it is implemented on part of the land destined for the agricultural production, furthermore, the land to be used for the forestation for wood production is relatively small, that is 0.50 to $4.23 \%$ of the agricultural land for the cultures considered in this study: coffee (natural), corn, beans and soybeans.
\end{abstract}

KEYWORDS: energy, reforestation, drying.

\footnotetext{
${ }^{1}$ Doutor em Engenharia Agrícola, Pesquisador, Embrapa Café, Parque Estação Biológica - PqEB - s/nº, Brasília - DF, paulo.junior@embrapa.br.

${ }^{2}$ Eng $^{\mathrm{o}}$ Eletricista, Professor, Departamento de Engenharia Agrícola, Universidade Federal de Viçosa, Viçosa - MG.

${ }^{3}$ Eng ${ }^{o}$ Agrícola e Ambiental, Mestrando, Departamento de Engenharia Agrícola, Universidade Federal de Viçosa,Viçosa - MG.

Recebido pelo Conselho Editorial em: 14-7-2005

Aprovado pelo Conselho Editorial em: 7-3-2006
} 


\section{INTRODUÇÃO}

Entre os diversos fatores que influenciam na preservação da qualidade dos produtos agrícolas, o teor de água do produto é um dos principais elementos a serem considerados. A secagem consiste na retirada parcial da água dos produtos até que atinjam um teor de água adequado, permitindo o armazenamento sem que sofram perdas significativas tanto quantitativas quanto qualitativas.

No processo de secagem, para que a água possa ser removida do grão, torna-se necessário o fornecimento de certa quantidade de energia ao produto, quantidade essa que dependerá do produto e dos seus teores iniciais e finais de água. A escolha de um sistema mais adequado de secagem, independentemente do produto a ser trabalhado, requer prévio estudo do custo da energia gasta no processo para atingir os níveis de água desejados.

Segundo ROSSI \& ROA (1980), secadores que processam grandes quantidades de produto em pouco tempo, apresentam eficiência energética média da ordem de $40 \%$, sendo que a maioria dos secadores comerciais empregados na secagem de produtos agrícolas utiliza energia proveniente da combustão de derivados de petróleo e de lenha. Entretanto, quando o ar de secagem é indiretamente aquecido por meio de combustíveis fósseis, a energia gasta com a etapa de secagem pode alcançar $80 \%$ do gasto total de energia para o pré-processamento dos produtos (BROOKER et al., 1992).

A tendência atual do planejamento integrado dos recursos energéticos exige o estudo de diferentes alternativas de fontes para a secagem de grãos. Aspectos tais como, minimização do impacto ambiental e escassez de recursos não-renováveis devem ser considerados na seleção das fontes de energia, ou seja, os fatores econômicos, isoladamente, não podem ser os determinantes para essa seleção.

Este trabalho tem como principal objetivo determinar o custo e a viabilidade de produção da lenha de eucalipto necessária para secagem de diferentes produtos agrícolas, em função do preço da lenha e do valor da terra, quando se utiliza parte da área destinada à produção agrícola para o reflorestamento.

\section{MATERIAL E MÉTODOS}

A energia requerida para a secagem foi determinada utilizando-se do calor latente de vaporização da água dos produtos considerados (café, milho, arroz, feijão e soja). Segundo HALL (1980), o calor latente de vaporização da água de produtos agrícolas está inversamente relacionado com seu teor de água, podendo ser adotado, de modo geral, o valor de $2.930,20 \mathrm{~kJ} \mathrm{~kg}^{-1}$ para produtos com teor de água entre 15 e $35 \%$ b.u. e $2.720,20 \mathrm{~kJ} \mathrm{~kg}^{-1}$ para produtos entre $35-60 \%$ b.u.

Foi considerada como fonte de energia para secagem, neste estudo, a lenha de eucalipto (Eucalyptus sp.) com 15\% de água, com preço médio variando de US\$10,00 a US\$15,00 por $\mathrm{m}^{3}$ de combustível. Para a determinação da quantidade de combustível necessária para a secagem, foram consideradas as seguintes propriedades da lenha de eucalipto: poder calorífico superior a $13.813,80 \mathrm{~kJ} \mathrm{~kg}^{-1}$, poder calorífico inferior a $12.207,38 \mathrm{~kJ} \mathrm{~kg}^{-1}$ e massa específica de $390 \mathrm{~kg} \mathrm{~m}^{-3}$ (BRASIL, 1997). A eficiência térmica global do equipamento de secagem foi considerada em $40 \%$ (ROSSI \& ROA, 1980).

Considerou-se que, para a obtenção anual de lenha, serão implantados sete povoamentos florestais de mesma área, visando-se ao abastecimento sustentado a partir do sétimo ano após o início do empreendimento. Cada povoamento será capaz de fornecer a quantidade de matéria-prima energética necessária para a secagem da produção agrícola de cada ano. 
A estimativa do custo de produção da lenha de eucalipto levou em consideração os custos de implantação, manutenção e exploração ao longo do período estudado. Na composição desses custos, foram considerados os custos referentes à mão-de-obra, materiais, insumos e equipamentos. Para a determinação dos custos das diversas fases e respectivas operações florestais, adotou-se o período de planejamento de 21 anos, com ciclos de cortes a cada sete anos. Para a produtividade média anual, foi considerado o valor de $40 \mathrm{~m}^{3} \mathrm{ha}^{-1}$ ano $^{-1}$, no primeiro corte. Para o segundo e terceiro cortes, foram adotados os valores de 34 e $28 \mathrm{~m}^{3} \mathrm{ha}^{-1} \mathrm{ano}^{-1}$, respectivamente (AFONSO JÚNIOR \& OLIVEIRA FILHO, 1998).

Outro componente do custo considerado foi o de oportunidade de utilização da terra, determinado como sendo os juros sobre o valor de venda da terra, própria para lavoura, considerandose a taxa de $10 \%$ ao ano. Foram considerados os preços médios de um hectare de terra, variando entre US\$ 500,00 e US\$2.000,00 (IBGE, 1997). O custo de oportunidade foi adotado como sendo de $10 \%$ ao ano.

Com relação aos gastos com a administração do empreendimento (contabilidade, folha de pagamento, etc.) e com o local do reflorestamento (transporte de pessoal, encarregados, etc.), foi considerado um percentual de $10 \%$ sobre o custo do investimento na determinação do custo administrativo do reflorestamento.

Para realizar a análise da viabilidade econômica do reflorestamento, foram empregados métodos que consideram a variação do capital investido em função de sua distribuição ao longo do período do investimento. Foram utilizados os critérios de avaliação de valor presente líquido (VPL), taxa interna de retorno (TIR) e tempo de retorno do capital investido (TRC), conforme eqs.(1), (2) e (3) (LAPPONI, 1996).

\section{Valor presente líquido - VPL}

Segundo LAPPONI (1996), o Valor Presente Líquido compara todas as entradas e saídas de dinheiro na data inicial do projeto, descontando todos os valores futuros do fluxo de caixa na taxa de juros k que mede o custo de capital. A expressão geral do VPL do projeto de investimento é dada pela eq. (1).

$$
\mathrm{VPL}=\mathrm{I}+\sum_{\mathrm{t}=1}^{\mathrm{n}}\left[\frac{\mathrm{R}_{\mathrm{t}}}{(1+\mathrm{k})^{\mathrm{t}}}\right]+\frac{\mathrm{Q}}{(1+\mathrm{k})^{\mathrm{n}}}
$$

em que,

VPL - valor presente líquido, R\$;

I - investimento de capital na época zero, $\mathrm{R} \$$

$\mathrm{R}_{\mathrm{t}}$ - retornos depois de descontados os impostos, ou imposto de renda, $\mathrm{R} \$$

$\mathrm{n}$ - prazo da análise do projeto ou vida útil, ano;

$\mathrm{k}$ - taxa de juros, decimal;

$\mathrm{Q}$ - valor residual do projeto no final do prazo da análise, $\mathrm{R} \$$, e

$\mathrm{t}$ - tempo, ano.

Portanto, o critério do método do VPL estabelece que, enquanto o valor presente das entradas for maior que o valor presente das saídas, que foi calculado com a taxa de juros $\mathrm{k}$ que mede o custo de capital, o projeto deve ser aceito. Resumindo, sempre que: (i) VPL $>0$, o projeto deve ser aceito; (ii) $\mathrm{VPL}=0$ é indiferente aceitar ou não, e (iii) $\mathrm{VPL}<0$, o projeto não deve ser aceito. 


\section{Taxa interna de retorno - TIR}

Segundo LAPPONI (1996), é a taxa de juros que anula o VPL, isto é, que torna VPL $=0$. Como a soma de todos os capitais na data inicial do projeto de investimento deve ser igual a zero, impõe-se essa condição na fórmula do VPL do projeto. A eq. (2) apresenta a fórmula para cálculo da TIR.

$$
\mathrm{VPL}=0=\mathrm{I}+\sum_{\mathrm{t}=1}^{\mathrm{n}}\left[\frac{\mathrm{R}_{\mathrm{t}}}{(1+\mathrm{TIR})^{\mathrm{t}}}\right]+\frac{\mathrm{Q}}{(1+\mathrm{TIR})^{\mathrm{n}}}
$$

em que,

TIR - taxa interna de retorno, decimal;

VPL - valor presente líquido, R\$;

$\mathrm{I}$ - investimento de capital na época zero, $\mathrm{R} \$$;

$\mathrm{R}_{\mathrm{t}}$ - retornos depois de descontados os impostos, ou imposto de renda, $\mathrm{R} \$$

$\mathrm{T}$ - tempo, anos;

$\mathrm{N}$ - prazo da análise do projeto ou vida útil, ano, e

$\mathrm{Q}$ - valor residual do projeto no final do prazo da análise, $\mathrm{R} \$$.

O critério do método da taxa interna de retorno estabelece que, enquanto o valor da TIR for maior que o valor do custo de capital k, o projeto deve ser aceito, isto é, sempre que: (i) TIR > k, o projeto deve ser aceito; (ii) $\mathrm{TIR}=\mathrm{k}$, é indiferente aceitar ou não, e (iii) $\mathrm{TIR}<\mathrm{k}$, o projeto não deve ser aceito.

\section{Taxa de retorno do capital - TRC}

É o período de tempo necessário para que o investimento inicial aplicado seja recuperado. O tempo de retorno do capital pode ser calculado considerando a renda anual não descontada, por meio da eq. (3).

$$
\mathrm{TRC}=\frac{\mathrm{C}_{\mathrm{i}}}{\mathrm{R}_{\mathrm{a}}}
$$

em que,

$\mathrm{C}_{\mathrm{i}}$ - capital inicial, $\mathrm{R} \$$, e

$\mathrm{R}_{\mathrm{a}}$ - renda anual não descontada, $\mathrm{R} \$$.

O critério do método do tempo de retorno de capital estabelece que: (i) TRC > vida útil do projeto, o projeto não deve ser aceito; (ii) TRC = vida útil do projeto, é indiferente aceitar ou não, e (iii) $\mathrm{TRC}<$ vida útil do projeto, o projeto deve ser aceito.

\section{RESULTADOS E DISCUSSÃO}

Na Tabela 1, estão apresentadas a energia requerida e a quantidade de lenha necessária para secagem de diversos produtos agrícolas, utilizando equipamento com eficiência térmica global de 40\%, considerando-se seus teores de água para a colheita e a armazenagem.

Observa-se que produtos com teores de água na colheita mais elevados requerem maior quantidade de energia para a realização do processo de secagem e, consequientemente, mais combustível para a evaporação da água contida no produto até o teor de água adequado para armazenamento seguro. 
TABELA 1. Quantidade de lenha e energia necessária para a secagem de alguns produtos agrícolas, em função dos seus teores de água na colheita e armazenagem.

\begin{tabular}{lcccc}
\hline Produto Agrícola & $\begin{array}{c}\text { Teor de Água } \\
\text { na Colheita }\end{array}$ & $\begin{array}{c}\text { Teor de Água na } \\
\text { Armazenagem }\end{array}$ & $\begin{array}{c}\text { Energia Requerida } \\
\text { para Secagem }\end{array}$ & $\begin{array}{c}\text { Quantidade de } \\
\text { Lenha Necessária }\end{array}$ \\
\cline { 2 - 5 } & (\%b.u. $)$ & $(\%$ b.u. $)$ & $\begin{array}{c}(1.000 \times \text { kJ por tonelada } \\
\text { de produto seco })\end{array}$ & $\begin{array}{c}\left(\mathrm{m}^{3} \text { por tonelada de }\right. \\
\text { produto seco })\end{array}$ \\
\hline Café (coco) & 45 & 11 & $4.204,98$ & 0,88 \\
Milho & 25 & 13 & $1.172,07$ & 0,25 \\
Arroz & 20 & 13 & 640,98 & 0,13 \\
Feijão & 25 & 13 & $1.172,07$ & 0,25 \\
Soja & 20 & 11 & 824,09 & 0,17 \\
\hline
\end{tabular}

Na Tabela 2, encontram-se a área plantada e a produção brasileira dos produtos estudados, e a área necessária para produção anual de lenha de eucalipto para secagem de toda produção, considerando a utilização de equipamento de secagem com eficiência térmica de $40 \%$. A Tabela 2 contém, também, a porcentagem da área utilizada para a lavoura a ser destinada ao povoamento florestal.

De modo geral, pode-se notar que a parcela de terra a ser utilizada para a produção anual de lenha para secagem é relativamente pequena quando comparada à área destinada à produção agrícola, variando de $0,50 \%$ para a cultura do feijão até $4,23 \%$ para a cultura do café. É importante ressaltar a possibilidade de utilização de outras fontes alternativas de biomassa para secagem, tais como, sabugo do milho, casca do arroz, restos culturais da renovação da lavoura de café e demais resíduos agrícolas.

Na Figura 1, verifica-se a composição dos custos operacionais das diversas fases da atividade de reflorestamento de um hectare com eucalipto para o período de planejamento estabelecido, considerando-se os diferentes valores estudados para terras de lavoura. Pode-se verificar, por essa figura, que as maiores contribuições na composição do custo total do reflorestamento ocorrem no primeiro ano do investimento e nos anos 7; 14 e 21, em decorrência da maior parcela na formação dos custos do empreendimento ser devida às etapas de implantação e exploração florestal e, ainda, que a parcela referente ao custo da terra tem influência significativa sobre o custo total do reflorestamento.

TABELA 2. Área plantada, produção brasileira dos produtos estudados, área necessária para a produção anual de lenha de eucalipto para secagem de toda produção e porcentagem da área utilizada para a lavoura a ser destinada ao povoamento florestal, no ano de 1996.

\begin{tabular}{lcccc}
\hline \multirow{2}{*}{$\begin{array}{c}\text { Produto } \\
\text { Agrícola }\end{array}$} & $\begin{array}{c}\text { Área } \\
\text { Plantada* }\end{array}$ & Produção* & $\begin{array}{c}\text { Área Total } \\
\text { Necessária para o } \\
\text { Reflorestamento }\end{array}$ & $\begin{array}{c}\text { Relação entre Área } \\
\text { para o Reflorestamento } \\
\text { e Área Plantada }\end{array}$ \\
\cline { 2 - 5 } & $(\mathrm{ha})$ & $(\mathrm{t})$ & \multicolumn{1}{c}{$(\mathrm{ha})$} & $(\%)$ \\
\hline Café (coco) & 1.993 .485 & 2.685 .641 & 84.406 & 4,23 \\
Milho & 13.903 .726 & 32.185 .179 & 287.368 & 2,07 \\
Arroz & 3.959 .824 & 9.989 .839 & 46.382 & 1,17 \\
Feijão & 5.150 .825 & 2.822 .340 & 25.200 & 0,50 \\
Soja & 10.747 .762 & 23.562 .279 & 143.057 & 1,33 \\
\hline
\end{tabular}

* IBGE (1997) 


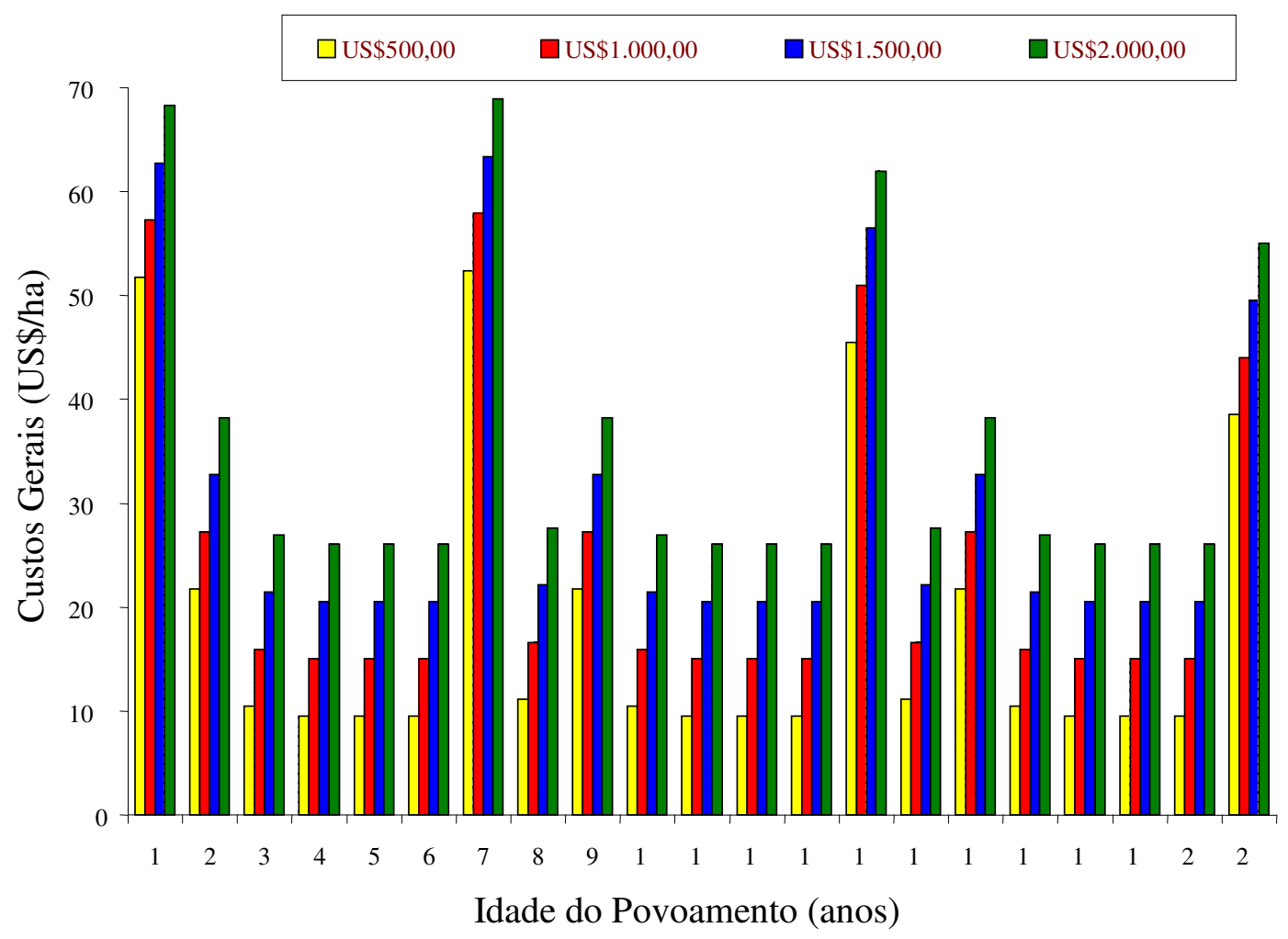

FIGURA 1. Custos gerais de reflorestamento de um hectare com eucalipto (Eucalyptus sp.) em função da idade do povoamento e do preço da terra.

Na Tabela 3, apresentam-se o custo da lenha reflorestada e os valores encontrados para a avaliação do valor presente líquido (VPL), taxa interna de retorno (TIR) e tempo de retorno do capital investido (TRC), em função do valor da terra e do preço comercial da lenha de reflorestamento.

A análise econômica realizada, tomando como referência os parâmetros técnicos e econômicos oriundos do levantamento dos custos e receitas da atividade de reflorestamento de um hectare de eucalipto em área de lavoura, é apresentada na Tabela 3. Analisando-se essa Tabela, observa-se ser economicamente viável, a uma taxa de oportunidade de $10 \%$ ao ano, para empreendimentos em áreas cujo preço da terra seja inferior a US\$ $1.000,00$ por ha, independentemente dos preços da lenha de reflorestamento considerados. Para valores do preço da terra de lavoura próximos a US\$ 1.500,00 por ha, o empreendimento apresentou-se economicamente viável apenas quando o preço comercial da lenha for igual ou superior a US\$12,50 por $\mathrm{m}^{3}$.

Entretanto, para locais onde o preço da terra atingir o valor de US\$2.000,00 por ha, a produção de lenha em área de lavoura torna-se economicamente vantajosa apenas quando o preço da lenha ultrapassar o preço de US $\$ 15,00$ por $\mathrm{m}^{3}$.

Torna-se importante ressaltar que o investimento em produção de lenha de eucalipto, em áreas de lavoura para suprimento de combustível para secagem da produção agrícola, mostrou-se, de modo geral, viável economicamente e capaz de promover economia nas despesas referentes ao consumo de combustíveis, uma vez que o custo de produção da lenha se apresentou inferior ao preço médio de aquisição desse combustível. Há, no entanto, de se considerar que terras normalmente utilizadas para reflorestamento são consideravelmente mais baratas, geralmente inferiores ao preço médio de US\$ 500,00 por ha (IBGE, 1997). E ainda que, em uma dada propriedade, podem existir porções de terra de valores que justifiquem o empreendimento de reflorestamento com fins energéticos. 
TABELA 3. Resultado da análise econômica utilizando os métodos de avaliação do valor presente líquido (VPL), taxa interna de retorno (TIR) e do tempo de retorno do capital (TRC), para diferentes valores dos preços da terra e da lenha comercial.

\begin{tabular}{|c|c|c|c|c|c|}
\hline $\begin{array}{c}\text { Preço } \\
\text { da } \\
\text { Terra } \\
\left(\mathrm{US} \$ \mathrm{ha}^{-1}\right)\end{array}$ & $\begin{array}{l}\text { Preço Comercial } \\
\text { da Lenha de } \\
\text { Reflorestamento } \\
\left(\mathrm{US} \$ \mathrm{~m}^{-3}\right)\end{array}$ & $\begin{array}{c}\text { VPL } \\
\text { (US\$) }\end{array}$ & $\begin{array}{l}\text { TIR } \\
(\%)\end{array}$ & $\begin{array}{c}\text { TRC } \\
\text { (anos) }\end{array}$ & $\begin{array}{c}\text { Custo Médio } \\
\text { da } \\
\text { Lenha } \\
\left(\mathrm{US} \$ \mathrm{~m}^{-3}\right)\end{array}$ \\
\hline \multirow{3}{*}{500,00} & 10,00 & 562,39 & 17,68 & 7,5 & \multirow{3}{*}{5,51} \\
\hline & 12,50 & $1.144,50$ & 23,70 & 7,4 & \\
\hline & 15,00 & $1.726,66$ & 28,60 & 7,3 & \\
\hline \multirow{3}{*}{$1.000,00$} & 10,00 & 86,71 & 11,15 & 7,7 & \multirow{3}{*}{7,12} \\
\hline & 12,50 & 668,82 & 17,68 & 7,5 & \\
\hline & 15,00 & $1.251,03$ & 22,85 & 7,4 & \\
\hline \multirow{3}{*}{$1.500,00$} & 10,00 & $-388,96$ & 4,89 & 7,8 & \multirow{3}{*}{8,74} \\
\hline & 12,50 & 193,40 & 12,16 & 7,6 & \\
\hline & 15,00 & 775,25 & 17,68 & 7,5 & \\
\hline \multirow{3}{*}{$2.000,00$} & 10,00 & $-864,64$ & $-1,40$ & Não retornável & \multirow{3}{*}{10,36} \\
\hline & 12,50 & $-282,54$ & 6,89 & 7,8 & \\
\hline & 15,00 & 299,57 & 12,89 & 7,6 & \\
\hline
\end{tabular}

* Taxa de câmbio (R\$1,68 / US\$).

** VPL com valores negativos indica inviabilidade econômica.

*** TIR com valores abaixo da taxa de juros considerada (10\%, neste estudo), ou com valores negativos, indica inviabilidade.

Esses aspectos econômicos somados aos crescentes problemas ecológicos enfrentados pela utilização de combustíveis fósseis indicam grande oportunidade para a produção de matéria-prima energética na propriedade, como prática viável para suprir as necessidades de energia na secagem da produção agrícola. Contudo, o reflorestamento para fins energéticos, em geral, não exclui a possibilidade de utilização da madeira e seus derivados para outras finalidades. Na propriedade rural, normalmente, ocorre a demanda de madeira para fins além do energético, que podem ser supridos pelo povoamento florestal.

\section{CONCLUSÕES}

O povoamento florestal com eucalipto em terras próprias para lavoura mostrou-se viável economicamente, para um valor médio da terra inferior a US\$1.000,00 por ha. A obtenção de combustível proveniente de reflorestamento em área de lavoura mostrou-se economicamente viável para locais com preço da terra de US\$1.500,00 por ha, apenas quando o preço comercial da lenha for igual ou superior a US\$12,50 por $\mathrm{m}^{3}$; para locais cujo preço da terra de lavoura for de US\$2.000,00 por ha, o empreendimento torna-se viável apenas quando o preço comercial da lenha ultrapassar o valor de US\$ 15,00 por $\mathrm{m}^{3}$. A área requerida para a produção de lenha necessária para a secagem de produtos agrícolas é relativamente pequena, quando comparada com a área destinada à produção agrícola.

\section{REFERÊNCIAS}

AFONSO JÚNIOR, P.C.; OLIVEIRA FILHO, D. Estudo da viabilidade econômica de produção de lenha de eucalipto (Eucalyptus sp.) em área de lavoura para secagem de produtos agrícolas. In: 
CONGRESSO BRASILEIRO DE ENGENHARIA AGRÍCOLA, 27., 1998, Poços de Caldas. Anais... Lavras: Sociedade Brasileira de Engenharia Agrícola, 1998. p.354-6.

BRASIL. Ministério de Minas e Energia. Balanço energético nacional. Brasília: MME, 1997. 151 p. BROOKER, D.B.; BAKKER-ARKEMA, F.W.; HALL, C.W. Drying and storage of grains and oilseeds. Westport: AVI, 1992. $450 \mathrm{p}$.

HALL, C.W. Drying and storage of agricultural crops. Westport: AVI, 1980. 381 p.

INSTITUTO BRASILEIRO DE GEOGRAFIA E ESTATÍSTICA - IBGE. Anuário estatístico do Brasil. Rio de Janeiro, 1997. 3/28 - 3/54 p.

ROSSI, S.J.; ROA, G. Secagem e armazenamento de produtos agropecuários com uso de energia solar e ar natural. São Paulo: Academia de Ciências do Estado de São Paulo, 1980. 295 p.

LAPPONI, J.L. Avaliação de projetos e investimentos: modelos em Excel. São Paulo: Lapponi Treinamento e Editora, 1996. 264 p. 